\title{
DINÂMICA CLIMÁTICA REGIONAL EM MUNICÍPIOS DA ZONA DA MATA, CAMPO DAS VERTENTES E SUL E SUDOESTE DE MINAS GERAIS: AS ONDAS DE CALOR E FRIO
}

\author{
OLIVEIRA, Daiane Evangelista de - daiane.evangelista.oliveira@gmail.com \\ Universidade Federal de Juiz de Fora / UFJF
}

\author{
ASSIS, Debora Couto de- cassis.debora@gmail.com \\ Universidade Federal de Juiz de Fora / UFJF
}

\author{
FERREIRA, Cássia de Castro Martins- cassia.castro@ufjf.edu.br \\ Universidade Federal de Juiz de Fora / UFJF
}

\begin{abstract}
RESUMO: O presente estudo teve por objetivo estudar, identificar e caracterizar, nas séries históricas de 1993 a 2011, os episódios de Ondas de calor e frio. Para isso, foi feito um recorte geográfico delimitando o objeto de estudo em áreas localizadas nos municípios da Zona da Mata (Juiz de Fora e Viçosa), Campo das Vertentes (Barbacena e Lavras), Sul e Sudoeste de Minas Gerais (Machado, Caldas e São Lourenço), buscando assim reconhecer os padrões espaço-temporais com que se manifestaram na área. Os dados utilizados foram de temperatura do ar máxima diária (Tmax) e mínima diária (Tmin), obtidas através do banco de dados do INMET. Os eventos de ondas foram identificados e contabilizados a partir de duas técnicas, sendo uma delas o período em que durante cinco ou mais dias registrou-se Tmax e Tmin superando a médias mais um desvio padrão; e a outra de dias consecutivos de temperatura superiores ou inferiores a $5^{\circ} \mathrm{C}$ em relação à média do período. Por fim, os dados foram espacializados com a finalidade de verificar a sua distribuição espacial, além de sua correlação com outras variáveis físicas. Os resultados indicaram que os municípios localizados à Oeste apresentaram um maior quantitativo de ondas de calor, enquanto que os à Leste apresentaram um maior quantitativo de ondas de Frio. Concluindo-se então que o relevo é o principal fator geográfico para a variabilidade dos regimes térmicos.
\end{abstract}

PALAVRAS-CHAVE: Variabilidade climática; temperatura do ar; Ondas de calor e frio; atividades agrícolas.

REGIONAL CLIMATE DYNAMICS IN CITIES FROM THE ZONA DA MATA, CAMPO DAS VERTENTES, SOUTH AND SOUTHWEST REGIONS OF MINAS GERAIS: HEAT AND COLD WAVES

ABSTRACT: The following essay aims to study, identify and characterize in historical series (1993 to 2011) the episodes of heat and cold Waves, having as its area of study cities in the Zona da Mata (Juiz de Fora and Viçosa), Campo das Vertentes (Barbacena and Lavras), South and Southwest (Machado, Caldas and São Lourenço) regions of Minas Gerais, seeking to recognize the space-time patterns in those manifestations. The data utilized were daily maximum air temperature (Tmax) and daily minimum air temperature (Tmin), obtained at the INMET database. The Wave events were identified and accounted for through two techniques, one of which being the period in which, during five days or more, Tmax and Tmin were superior to the averages and the standard deviation; and another, working with consecutive days of temperatures either more than $5^{\circ} \mathrm{C}$ above or below the average for the period. Finally, the data were spatialized in order to verify its spatial distribution, along with its correlations to other physical variants. Results have shown that the cities located West have a bigger amount of heat Waves, whereas those at East have more cold Waves. In conclusion, relief is the main geographic factor in the variability of thermal regimes

KEYWORDS: Climate variability; air temperature; heat and cold Waves; agricultural activities. 
DINÁMICA CLIMÁTICA REGIONAL EN MUNICIPIOS DE ZONA DA MATA, CAMPO DAS VERTENTES, SUR Y SUDOESTE DE MINAS GERAIS: LAS OLAS DE CALOR Y FRÍO

RESUMEN: El presente estudio tuvo por objetivo estudiar, identificar y caracterizar, en las series históricas de 1993 hasta 2011, episodio de Olas de calor y frío. Para eso, fue hecho un recorte geográfico delimitando el objeto de estudio en áreas localizadas en los municipios de Zona da mata (Juiz de Fora y Viçosa), Campos das Vertentes (Barbacena y Lavras), Sur y Sudoeste de Minas Gerais (Machado, Caldas e São Lourenço), buscando así reconocer los patrones espacio-temporales que se manifestaron en estas área. . Los datos utilizados consistieron en las temperaturas del aire con su máxima diaria (Tmax) y mínima diaria (Tmin), obtenidas a través de un banco de datos de INMET, además de todos los cultivos de datos realizados, en más de un municipio, a lo largo de 17 años o más de la serie estudiada. Los eventos de Olas de calor fueron identificados y contabilizados a partir de dos técnicas, siendo una de ellas el periodo que, a lo largo de cinco o más días, se ha registrado Tmax y Tmin, superando la medias más un desvío patrón; y otra trabajando en días consecutivos de temperaturas superiores o inferiores a $5^{\circ} \mathrm{C}$ en relación a la media del periodo. Por fin los datos fueron espacializados con la finalidad de verificar su distribución espacial, además de su correlación con otras variables físicas; Los resultados indicaron que los municipios localizados al Oeste presentaron mayor cuantitativo de Olas de calor, mientras que los de Leste presentaron Olas de frío, pudiendo así concluir que el relevo es el principal factor geográfico de la variabilidad de los regímenes térmicos.

PALABRAS CLAVE: variabilidad climática; temperatura del aire; Olas de calor y frío; actividades agrícolas.

\section{INTRODUÇÃO}

A variabilidade climática é a manifestação, no tempo e no espaço, de inúmeras interações do sistema climático terrestre. Esta exerce influência nas atividades humanas, principalmente naquelas que se destacam pela maior dependência das condições atmosféricas, como a sua saúde e a produção de alimentos, necessitando ser reconhecida.

A concepção de que a variabilidade anual e interanual de tipologias climáticas é produto de interações e condições específicas, em que particularidades se conectam e formam inúmeros arranjos específicos, vêm no sentido de melhorar o aproveitamento do clima enquanto recurso energético, assim como diminuir os impactos provenientes de suas excepcionalidades. A caracterização dos climas de determinado recorte têmporo-espacial permite que as mudanças, oscilações e alterações em seus regimes tenham seus padrões identificados.

Dentre as possíveis abordagens de apreensão do fenômeno climático podemos citar aquelas associadas à variabilidade térmica e a sazonalidade dos eventos. Os contrastes térmicos diários e anuais, que materializam os movimentos da Terra (rotação e translação) em teleconexão com as dinâmicas atmosféricas e as individualidades de cada sítio, produzem especificidades climáticas que podem se diferenciar de uma localidade para outra, assim como vir a repercutir na vida social.

Uma destas eventualidades climáticas (MONTEIRO, 1991), que influenciam direta ou indiretamente as populações, é aquela ligada aos episódios de temperaturas extremas do ar associados às Ondas de calor e Ondas de frio, que são extremos térmicos em relação às normais climatológicas por período e que podem trazer transtornos de acordo com a intensidade e duração de seus eventos. Os contrastes térmicos que existem naturalmente nos ciclos dos regimes climáticos apresentam eventos que fogem a habitualidade e que podem 
vir a significar transtornos à sociedade, dado ao excepcionalismo com que se manifestam.

Assim, estratégias ambientais e de saúde pública relativas à compreensão do clima se portam como de fundamental importância, pois contribuem para resguardar as condições de vida e de bem-estar, uma vez que há inúmeras relações que podem ser estabelecidas entre a dinâmica climática e a saúde humana e vegetal, o que em síntese são materializações de vida e a produção do espaço. Os seres vivos, por exemplo, são sensíveis às alterações climáticas e possuem particularidades que tem relação com questões ligadas às condições do ambiente. O perfil ótimo de temperatura do ar que adotam é variável e sua adaptação se diferencia tanto de espécie para espécie, como entre os indivíduos, que apresentam condições bioclimáticas ideais que são percebidas pelas sensações de conforto e desconforto térmico.

Em termos de seres humanos, o risco vinculado à exposição a extremos de temperaturas são diversos e tem relação direta com a vulnerabilidade das populações à magnitude dos eventos, pois agravam os problemas e afetam a vida social ao acentuarem à exposição das populações mais vulneráveis, como as crianças, idosos e pessoas em situação de rua à casos de stress térmico (MARTO, 2005; MONTEIRO et al., 2012; MATEUS, 2014; ALEIXO et al., 2013). Também a influência nos regimes alimentícios daquelas populações que têm na agricultura a sua subsistência e nas plantações uma forma de garantir o sustento, precisam ser considerados.

Diversos podem ser os prejuízos associados ao setor agrícola quando em ocorrência de episódios de extremos térmicos, como os incêndios florestais, e os consequentes impactos ambientais das queimadas, e as perdas de produtos e safras. Numerosos são os riscos ligados à exposição a altas ou baixas temperaturas do ar, os quais muitas vezes ocorrem pela falta de um sistema de monitoramento eficaz e que possibilite diminuir os impactos, identificar os episódios e pensar estratégias para reduzir as ameaças frente a estes. A avaliação dos possíveis efeitos, que acentuam os danos e agravam as perdas em anos considerados atípicos, assim como os impactos dos extremos de temperatura nos sistemas ambientais e que trazem impactos econômicos e sociais, precisam estar dentre as políticas de gestão e ordenamento do território.

Partindo deste contexto, o objetivo deste estudo foi identificar anomalias de temperatura do ar, materializadas sob a forma de eventos de Ondas de calor e de Ondas de frio, tendo como área de estudo municípios localizados na Zona da Mata mineira (Juiz de Fora e Viçosa), Campo das Vertentes (Lavras e Barbacena) e Sul e Sudoeste de Minas (Caldas e Machado) e como recorte temporal os anos entre 1993 e 2011.

\section{REFERENCIAL TEÓRICO: ONDAS DE CALOR E DE FRIO}

Em primeiro lugar cabe situar a temática das Ondas de Temperatura nas pesquisas de Climatologia, em especial na climatologia Brasileira. Esta faz parte dos estudos de variabilidade climática, principalmente aqueles ligados à climatologia dinâmica, nos quais a gênese e repercussão dos elementos climáticos são parte fundamental para o entendimento de suas interações socioambientais. As "Ondas" climáticas são pesquisadas em muitos países, em especial os da Europa, como por exemplo Portugal, onde diversos estudos são 
encontrados (ALEIXO et al., 2013; BOTELHO; GANHO, 2012; CALADO et al., 2004; CUNHA; LEAL, 2013; CUNHA, 2012; FREITAS, 2011; GUERREIRO, 2011; MATEUS, 2014; MARTO, 2005, MONTEIRO et al., 2012; TAVARES; CUNHA, 2007). Em termos de climatologia brasileira há alguns estudos (BITENCOURT et al., 2016; BARCELLOS et al., 2009; ESCOBAR, 2007), dentre os quais há estudos em parceria com pesquisas portuguesas, enquanto outros com investigações no Brasil.

O vocábulo "Onda" é, em climatologia, atribuído à ocorrência de temperaturas extremas do ar, por vários dias consecutivos e em um limiar inferior/superior das normais climatológicas do período. Tais sequências de fenômenos meteorológicos anômalos (FIRPO, 2008) representam períodos prolongados em que as temperaturas do ar diurnas e noturnas são excepcionalmente elevadas ou reduzidas. A expressão Tempo Canicular também pode ser empregada para esta definição.

Não há um consenso no que tange à definição do que representam os episódios ondulatórios (ALVES, 2016), mas há critérios de excepcionalidade (FANTE; ARMOND, 2016) que são considerados. O que tem de comum nas concepções é o fato de que se considera para os cálculos de identificação as temperaturas máximas e mínimas do ar em seus padrões médios nas Normais Climatológicas e não a temperatura média do ar padronizada, uma vez que são os extremos térmicos que se busca identificar.

Há ainda, algumas tentativas que consideram classes fixas de valores para sua identificação, dentre as quais podemos citar duas como principais. A da Organização Meteorológica Mundial (OMM: WMO-TD No. 1071), que considera uma Onda como sendo o período de pelo menos seis dias consecutivos em que a temperatura do ar é $5^{\circ} \mathrm{C}$ superior (calor) ou inferior (frio) ao valor médio das temperaturas do ar do período de referência, e que tem seu próprio índice, denominando Heat Wave Duration Index (HWDI). $E$ a do Painel Intergovernamental sobre Mudanças Climáticas (IPPCC, 2001) que recomenda considerar um período de cinco ou mais dias consecutivos com temperaturas do ar diárias excedendo $5{ }^{\circ} \mathrm{C}$ ou mais à temperatura média do ar.

Porém, há distintos climas no globo, produto de características diversas de seu local de origem e que possuem amplitudes que podem ser simplórias perto de um limiar de $5^{\circ} \mathrm{C}$ em relação à média, ultrapassando em muito tais valores e não podendo serem enquadrados em uma classe fixa de valores. Assim, alguns países utilizam de critérios fixos, como os da OMM e do IPCC, mas os redefinem à partir de suas próprias características térmico-ondulatórios.

O clima Europeu, por exemplo, que pela sua localização geográfica pode ser muito frio nos países ao Norte ou apresentar grandes amplitudes na região mediterrânea (CUNHA, 2012, 2013; IPMA, 2003) adota critérios múltiplos para a identificação das classes. Em Portugal é adotada a definição do Índice de Duração da Onda de Calor (HWDI) da OMM, enquanto que na Holanda, Bélgica, Dinamarca e Luxemburgo é o período de pelo menos 5 dias consecutivos em que a temperatura máxima excede os $25^{\circ} \mathrm{C}$, sendo em pelo menos 3 dias superior aos $30^{\circ} \mathrm{C}$, que é chamado de Onda.

Em termos de América, ao Norte do continente é considerado Onda de calor o período de 3 ou mais dias consecutivos superiores a $32,2{ }^{\circ} \mathrm{C}$. No entanto, essa classificação pode vir a mascarar certas informações, uma vez que 
há lugares como o México e o interior Estadunidense onde há registros frequentes de temperaturas do ar superiores.

Para a América do Sul, especificamente para o Brasil, há estudos principalmente para a região que engloba os Estados do Rio Grande do Sul, Santa Catarina e Paraná (ALVES, 2016; FIRPO, 2008; MENDONÇA; ROMERO, 2012; WOLLMANN; GALVANI, 2012; SILVEIRA et al., 2017), enquanto que para a região Sudeste há poucos (FANTE; ARMOND, 2016; FANTE; SANT'ANNA NETO, 2017). Mesmo havendo pesquisas que demonstram que o clima do Sudeste é de transição climática e apresenta amplitudes sazonais significativas, não há muitos estudos que tenham as Ondas térmicas como objeto de estudo nesta região.

O sul de Minas Gerais, por exemplo, caracterizado por geadas, muito frequentes nos meses de inverno e que "ocorrem quando a temperatura do ar próxima à superfície exposta cai abaixo de $0^{\circ} \mathrm{C}^{\prime \prime}$ (ALVES, 2016, p.43), precisa ser objeto de estudos climáticos que englobem, de forma detalhada, a análise de suas tipologias climáticas. Segundo Escobar (2007, p.242) "a ocorrência de Ondas de frio na região Sudeste do Brasil estão estreitamente relacionadas com a variabilidade dos sistemas sinóticos que afetam o continente sul americano", os quais, influenciados por padrões anômalos de circulação de duração diferente daquela observada pela escala sinótica, favorecem as incursões de ar frio para o interior do Brasil (ESCOBAR, 2007).

Também a complexidade e incertezas que permeiam as interações atmosfera-ambiente em regiões montanhosas, contribuem para que o sul de Minas Gerais seja uma área de temperaturas do ar mais baixas. Conforme ressaltado por Nimer (1979, p.283) "embora o afastamento das influências marítimas e o aumento da latitude exerçam papel importante no comportamento das temperaturas mínimas, na Região Sudeste o mais importante é assumido pelo relevo". A influência deste na variabilidade anual e interanual da temperatura do ar pode ser visualizada a partir de vários aspectos, dentre os quais podemos citar a distinta recepção de radiação solar, dada ao direcionamento e disposição das faces das vertentes do relevo, que favorece ou não a incidência dos raios solares, que acentuam a ocorrência de episódios ondulatórios (ARMANI, 2009); a rarefação do ar, pelos componentes adiabáticos de compressão e dispersão que ocorrem como o aumento da altitude, e que tornam menos aquecidas as camadas inferiores e a cada 100 metros é esperado um decréscimo de 0,5 a $1{ }^{\circ} \mathrm{C}$ (MENDONÇA; DANNIOLIVEIRA, 2011); e os processos de inversão térmica, quando a maior densidade do ar frio favorece que este fique retido em uma camada mais próxima à superfície (MENDONÇA; DANNI-OLIVEIRA, 2011).

As Ondas de calor costumam ocorrer principalmente durante períodos de verão, quando campos de pressão semi-fixos bloqueiam a chegada de frentes frias, produzindo bolsões de ar quente aquecidos durante os dias. A permanência e atuação destes sistemas de Alta pressão, que favorecem o aumento do calor próximo à superfície, atrelados aos padrões de cobertura da Terra e/ou a fenômenos climáticos globais, fazem com que as temperaturas do ar (mínimas e máximas) venham a ser mais acentuados que o habitual (VIANELLO, 2012; BARRY; CHORLEY, 2013).

Em ambos casos, a gênese das Ondas podem estar correlacionadas com fenômenos de larga escala, assim como pela interação dos sistemas sinóticos com o relevo regional. Dentre os mecanismos atmosféricos que mais podem influenciar a formação de tipologias climáticas que produzem episódios de 
Ondas de calor e Ondas de frio estão aqueles atrelados às anomalias de Temperatura da Superfície do Mar, como à Oscilação Decenal do Pacífico e os fenômenos ENOS de El Niño e La Niña (PEZZA, 2003), e aos campos de pressão permanentes da circulação atmosférica global, como a Alta Subtropical do Atlântico Sul (ASAS).

Os episódios de frios intensos ou de calor superior à média podem ser frutos da materialização destes fenômenos naturais, que por sua vez apresentam ciclos de escalas temporais distintas e têm relações de teleconexão com outras regiões do globo (CAVALCANTI et al., 2009), mas que por diversas vezes já terem ocorrido foram incorporados com naturalidade pelas pessoas. Os indivíduos acabam por "se habituarem a conviver com os paroxismos climáticos, os riscos que the estão associados acabam por se revestir de pouca importância, quer no quadro dos estudos acadêmicos, quer no contexto dos planos operacionais de emergência e socorro" (CUNHA, 2012, p. 106), fazendo reportar a necessidade de que práticas que visam o reconhecimento de que há ciclos e ritmicidade também nos processos e mecanismos atípicos que ocorrem em certas regiões do globo sejam planejadas. A adaptabilidade perpassa a identificação e assimilação dos ciclos naturais.

\section{CARACTERIZAÇÃO DA ÁREA DE ESTUDO}

A área de estudo compreende seis municípios do Estado de Minas Gerais (Juiz de Fora, Barbacena, Viçosa, Machado, São Lourenço, Lavras e Caldas) localizados nas regiões de planejamento Sul, Zona da Mata e Campo das Vertentes. A escolha se deu após identificação de todas estações convencionais disponíveis na rede INMET nas três regiões, vindo a ser estes os que apresentaram um menor quantitativo de dias com dados falhos. A localização dos municípios estudados e as estações de coleta podem ser observadas no Figura 1 e as principais informações socioambientais dos municípios na tabela 1 , a seguir. 


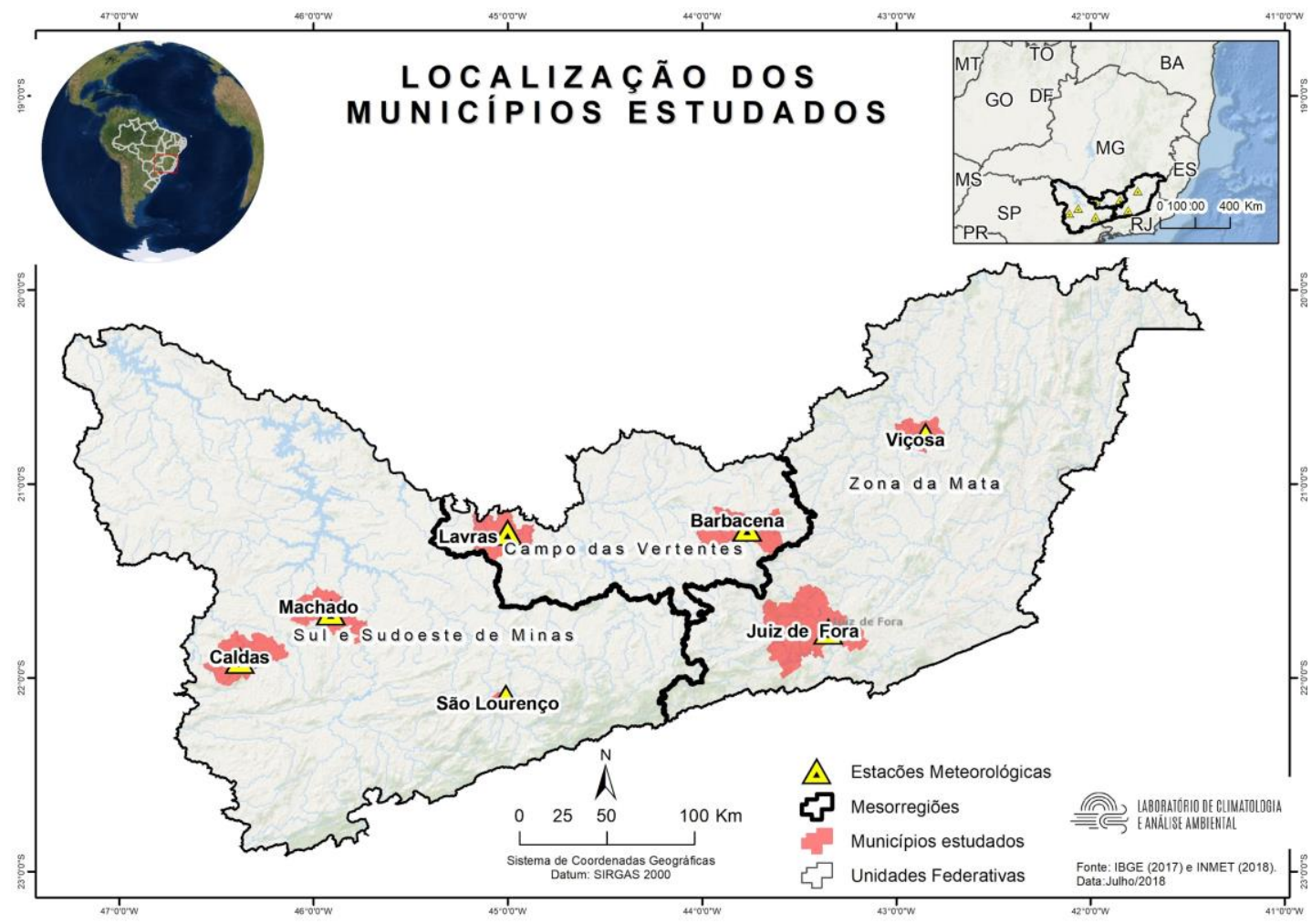

Figura 1 - Localização da área de estudo. Fonte: IBGE, 2010; INMET, 2018. Organizado pelas autoras.

\begin{tabular}{|l|c|c|}
\hline \multicolumn{1}{|c|}{ Municipio } & Altitude & Bacia hidrográfica \\
\hline Juiz de Fora & $940 \mathrm{~m}$ & rio Paraiba do Sul \\
\hline Lavras & $919 \mathrm{~m}$ & rio Grande \\
\hline São Lourenço & $900 \mathrm{~m}$ & rio Grande \\
\hline Viçosa & $689 \mathrm{~m}$ & rio Doce \\
\hline Machado & $873 \mathrm{~m}$ & rio Grande \\
\hline Caldas & $1300 \mathrm{~m}$ & rio Grande \\
\hline Barbacena & $1126 \mathrm{~m}$ & rio Grande \\
\hline
\end{tabular}

Tabela 1 - Aspectos socioambientais da área de estudo. Fonte: IBGE, 2018. Organizado pelas autoras.

A região apresenta um clima que possui suas gêneses atreladas principalmente à atuação da mTa (massa Tropical Atlântica) e da massa Polar Atlântica, que interagindo com a própria morfologia do terreno e os padrões de cobertura da terra produz um tipo climático denominado Tropical (CONTI, 1989), com variações para o Tropical com Estação Chuvosa em Caldas e o Tropical de Altitude nos demais municípios (KOPPEN; GEIGER, 1936). Tais dinâmicas se materializam sob a forma de tipologias climáticas distintas, que tem na sazonalidade dos elementos meteorológicos uma das possibilidades para a compreensão da variabilidade climática regional (Figura 2). 


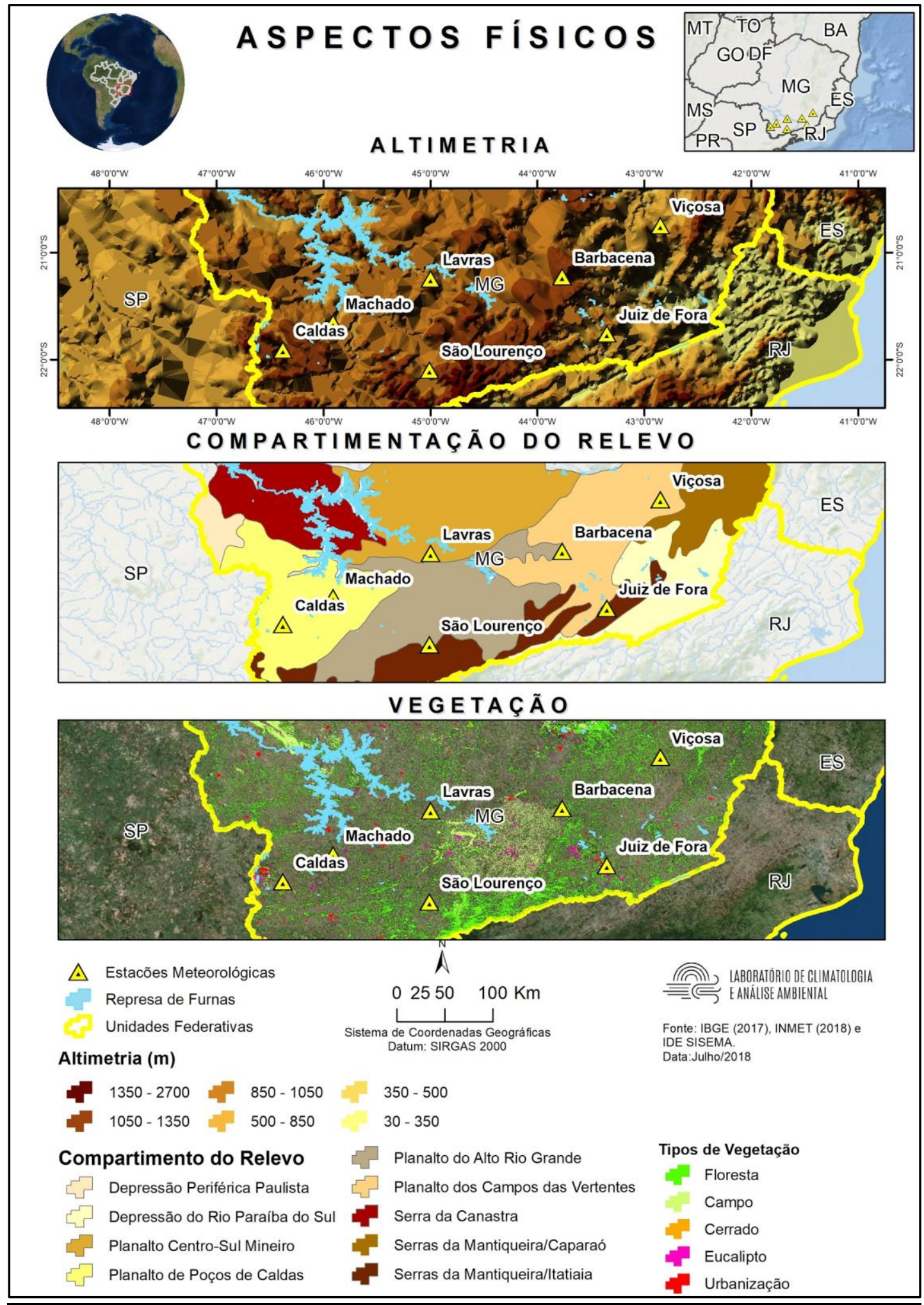

Figura 2 - Aspectos físicos da área de estudo. Fonte: IBGE, 2017; INMET, 2018; IDE SISEMA, 2018. 
Segundo informações das normais climatológicas (INMET, 2018) do período 1981-2010 é possível afirmar que há duas estações meteorológicas distintas, uma mais seca e fria, entre os meses de abril a setembro, e uma mais quente e chuvosa, de outubro a março. Os municípios menos chuvosos são Viçosa $(1289,0 \mathrm{~mm})$ e Lavras $(1461,8 \mathrm{~mm})$, enquanto Juiz de Fora $(1624,0 \mathrm{~mm})$ é o mais chuvoso. Os menores registros de Tmin do ar foram encontrados em Caldas $\left(12,3^{\circ} \mathrm{C}\right)$ e São Lourenço $\left(13,5^{\circ} \mathrm{C}\right)$, enquanto os Tmáx mais elevadas foram registrados em Machado $\left(27,5^{\circ} \mathrm{C}\right)$, São Lourenço $\left(27,3^{\circ} \mathrm{C}\right)$ e Lavras $\left(27,2^{\circ} \mathrm{C}\right)$. Esta configuração climática pode ter relação direta com os aspectos físicos da região.

A amplitude topográfica (entre 650 e 2700m), atrelada à sua localização no domínio morfoclimático dos Mares de Morros (AB'SABER, 1970) e ao fato dos municípios estarem próximos a compartimentos morfológicos como as serras do Mar e da Mantiqueira e inseridos em planaltos (planalto do Campo das Vertentes, planalto de Caldas, planalto do Alto Rio Grande) favorece para que sejam acentuados os processos adiabáticos na região. A formação de geadas, inversões térmicas, chuvas orográficas, entre outras manifestações climáticas, possuem relação direta com esses tipos de formas do relevo.

Também a proximidade com a represa de Furnas precisa ser considerada, pois o fato desta apresentar $1.440 \mathrm{~km}^{2}$ de área alagável e um volume de 22,59 bilhões de $\mathrm{m}^{3}$ significa um corpo hídrico de dimensões significativas e que pode influenciar no regime hidroclimático da região. A disponibilidade hídrica e os regimes térmicos têm suas dinâmicas marcadas pela interação com corpos hídricos mais próximos.

No que tange aos aspectos de uso e cobertura da terra, constata-se que há a predominância de fragmentos de mata Atlântica, em coabitância com área de pastagens e que há áreas de cultivo de Eucaliptos na região. A produção do espaço regional apresenta resquícios dos processos históricos brasileiros e há, ainda hoje, alguns cultivos temporários ou permanentes. Porém, por representar uma região onde são frequentes os episódios de geadas no inverno, observa-se que novos cultivos mais adaptados foram inseridos na produção agrícola, assim como outros foram deixados de serem plantados, dada aos diversos stress térmicos a que eram acometidos.

O fato de haver em Juiz de Fora, Lavras e Viçosa um campus universitário federal e em Barbacena um campus do Instituto Federal de Educação, assim como a presença da Empresa Brasileira de Pesquisa Agropecuária - EMBRAPA em Juiz de Fora, pode vir a favorecer que estudos climáticos na região venham a ser feitos, com qualidade e contribuam para a identificação dos ciclos de excepcionalismo do clima. Em termos de população os municípios estudados são de portes diversos (gráfico 1), sendo Juiz de Fora (516.247 habitantes) e Barbacena (136.689) os mais populosos. Juiz de Fora é também o maior em extensão territorial e o que apresenta o maior PIB per capita $(25.990,24 \mathrm{R} \$)$, o que pode estar atrelado a outras formas de arrecadação, que não a agrícola.

\section{PROCEDIMENTOS METOdOLÓgICOS}

Primeiramente foram coletadas informações nas séries meteorológicas de temperatura do ar (máximas e mínimas diárias) do banco de dados do Instituto Nacional de Meteorologia (INMET), de estações que se localizassem nas regiões 
da Zona da Mata, Campo das Vertentes e Sul e Sudoeste do Estado de Minas Gerais. Estas tiveram seus dados falhos preenchidos (média do mês na localidade e média dos registros de 3 estações vizinhas mais próximas) e foram base para que o período entre os anos de 1993 e 2011 (19 anos) fosse escolhido como escala temporal para o estudo. A opção por este recorte de tempo se pautou no período com menor quantitativo de dados falhos e considerou como ponto amostral apenas os postos meteorológicos que não apresentaram falhas em mais que $10 \%$ do total de dias analisados (9130 dias). Os dias em que apenas um dos horários (00 ou 12 horas) também foram contabilizados como falha (tabela 2).

Tabela 2 - Quantitativo de dias com falhas no banco de dados por município, para a série 1993-2011. Fonte: organizado pelos autores.

\begin{tabular}{|c|c|c|c|c|c|}
\hline \multirow[b]{2}{*}{ 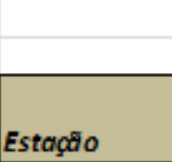 } & \multirow[b]{2}{*}{ Códligo } & \multicolumn{2}{|c|}{$\mathrm{N}^{\circ}$ de dlas com dados falhos } & \multicolumn{2}{|c|}{\begin{tabular}{|c} 
Porcentagemem relaç̆o ao total estudado \\
$(\%)$
\end{tabular}} \\
\hline & & Semnenhum dado & $\begin{array}{l}\text { Apenas em um } \\
\text { horarlo do dlla }\end{array}$ & Sem nen hum dado & $\begin{array}{l}\text { Apenas em um } \\
\text { horario do dla }\end{array}$ \\
\hline Machado & 83683 & $\begin{array}{r}66 \\
\end{array}$ & 132 & 0,01 & 1,45 \\
\hline Viçosa & 83642 & 10 & 209 & 0,11 & 2,29 \\
\hline S8̈o Lourenço & 83736 & 25 & 20 & 0,07 & 0,05 \\
\hline Lavras & 83687 & 71 & 0 & 0,78 & 0,00 \\
\hline Caidas & 83681 & 366 & 1136 & 4,01 & 12,44 \\
\hline Juiz de Fora & 83692 & 2014 & 234 & 22,06 & 2,56 \\
\hline Barbacena & 83692 & 341 & 190 & 3,7 & 0,0 \\
\hline
\end{tabular}

Após identificação e preenchimento dos dias com falhas no banco de dados, iniciou-se o procedimento de reconhecimento dos eventos de Ondas de calor e frio. Contudo, o fato de não haver um consenso, quanto ao reconhecimento dos episódios atípicos, contribuiu para que fossem adotadas duas metodologias, que teriam maior afinidade com a climatologia da área de estudo:

- Pautando-se nas premissas da OMM (WMO-TD No. 1071) e do IPCC (2007) considerou-se como Ondas climáticas os eventos cujas temperaturas do ar fossem superiores (calor) ou inferiores (frio) à normal climatológica diária, somadas ou subtraídas a $5^{\circ} \mathrm{C}$, o que as identificava com base em uma classe fixa de valor;

- Considerando-se como episódios atípicos, de Ondas de calor e frio, os dias em que os registros fossem superiores (calor) ou inferiores (frio) ao valor da normal climatológica diária acrescida ou subtraída ao desvio padrão por período. O emprego de tal metodologia é útil para identificar dentre os registros quais são os que são considerados como extremos para cada município da área de estudo.

Em ambos casos foram considerados apenas episódios com mais de 5 dias consecutivos com registro de temperatura do ar máxima maior ou igual a média da temperatura do ar máxima acrescida e temperatura do ar mínima menor ou igual a média da temperatura do ar mínima acrescida. Os cálculos das temperaturas do ar médias ocorreram através de estatística descritiva, 
estabelecendo um limiar específico para cada dia do ano por localidade. A identificação dos episódios nas séries se deu através de análises estatísticos e a contagem ocorreu de forma não mecanizada. Todos os cálculos foram realizados a partir do software Excel.

\section{RESULTADOS E DISCUSSÃO}

No que tange aos valores extremos da série estudada (tabela 3), constatou-se que o ano de 2007 foi atípico e apresentou registros de Tmax extrema de calor em Lavras $\left(36,4^{\circ} \mathrm{C}\right)$, Juiz de Fora $\left(34,8^{\circ} \mathrm{C}\right)$ e Barbacena $\left(35,1^{\circ} \mathrm{C}\right)$, enquanto que $\mathrm{o}$ ano de 1994 apresentou os menores registros de Tmin da série para São Lourenço $\left(-1,0^{\circ} \mathrm{C}\right)$, Lavras $\left(2,0^{\circ} \mathrm{C}\right)$, Caldas $\left(-5,0^{\circ} \mathrm{C}\right)$ e Barbacena $\left(35,1^{\circ} \mathrm{C}\right)$. Tais anos apresentaram dinâmicas climáticas de excepcionalidade (MONTEIRO, 1991) que também se materializaram no elemento meteorológico precipitação (OLIVEIRA, 2016). Enquanto 1994 foi um ano frio e chuvoso, o ano de 2007 foi mais quente e seco.

Tabela 3 - Registros de temperaturas da série. Fonte: INMET (1983-2011). Organizado pelos

\begin{tabular}{|l|l|c|c|c|c|c|c|c|}
\hline \multirow{2}{*}{ Código } & \multirow{2}{*}{ Estaçåo } & \multicolumn{2}{|c|}{ Tmáx. } & \multicolumn{2}{c|}{ Tmin. } & \multicolumn{3}{c|}{ Tméd. } \\
\cline { 3 - 9 } & & Valor & Dia & Valor & Dia & Tmax. & Tmin. & Tméd. \\
\hline 83683 & Machado & 36,8 & $25 / 01 / 2006$ & $-0,6$ & $18 / 07 / 2000$ & 27,64 & 14,68 & 21,14 \\
\hline 83642 & Viçosa & 37,6 & $10 / 09 / 1997$ & 3 & $25 / 07 / 1996$ & 26,89 & 15,73 & 20,48 \\
\hline 83736 & Săo Lourenço & 35,8 & $12 / 10 / 2002$ & -1 & $27 / 06 / 1994$ & 27,48 & 13,37 & 20,72 \\
\hline 83687 & Lavras & 36,4 & $17 / 10 / 2007$ & 2 & $27 / 06 / 1994$ & 27,83 & 15,40 & 22,91 \\
\hline 83681 & Caldas & 34,1 & $24 / 09 / 2003$ & -5 & $10 / 07 / 1994$ & 25,33 & 11,94 & 19,35 \\
\hline 83692 & Juiz de Fora & 34,8 & $17 / 10 / 2007$ & 6 & $09 / 06 / 1997$ & 24,73 & 15,62 & 20,00 \\
\hline 83689 & Barbacena & 35,1 & $17 / 10 / 2007$ & 1 & $10 / 07 / 1994$ & 25,07 & 13,95 & 19,93 \\
\hline
\end{tabular}

Superior a $27,0^{\circ} \mathrm{C}$ de Tmáx média se enquadram São Lourenço $\left(27,4^{\circ} \mathrm{C}\right)$, Machado $\left(27,6^{\circ} \mathrm{C}\right)$ e Lavras $\left(27,8^{\circ} \mathrm{C}\right)$, enquanto que Juiz de Fora apresenta a menor Tmáx média $\left(24,7^{\circ} \mathrm{C}\right)$, inferior a $25,0^{\circ} \mathrm{C}$. As menores Tmin médias são registradas em Caldas $\left(11,9^{\circ} \mathrm{C}\right)$, São Lourenço $\left(13,3^{\circ} \mathrm{C}\right)$ e Barbacena $\left(13,9^{\circ} \mathrm{C}\right)$ e em Viçosa foram registradas as Tmin médias mais elevadas $\left(15,7^{\circ} \mathrm{C}\right)$. É em Caldas que a amplitude entre as médias de Tmáx e Tmin foi maior $\left(13,4^{\circ} \mathrm{C}\right)$ e é em Juiz de Fora que foi menor $\left(9,1^{\circ} \mathrm{C}\right.$ de amplitude), no entanto, a média das temperaturas para Caldas $\left(19,3^{\circ} \mathrm{C}\right)$ demonstrou que este município apresenta temperaturas do ar tendentes a frias, dado que representou o menor valor dentre os municípios.

No que tange aos episódios de Ondas de calor e de frio, constatou-se que um maior quantitativo de episódios de frio em comparação com os de calor (Figura 3). A maior ocorrência de Ondas de calor foi encontrada nos municípios de Lavras $(n=55)$ e Machado $(n=47)$, enquanto que Barbacena $(n=37)$ e Viçosa $(n=38)$ apresentaram menor ocorrência destes eventos. Por sua vez, as Ondas de frio tiveram mais ocorrência em Juiz de Fora $(n=67)$ e Barbacena $(n=59)$. A maior amplitude entre a quantidade de Ondas de calor e frio foi encontrada em Juiz de Fora e Barbacena, com mais episódios de frio que calor.

A distribuição espacial de tais dados fez constatar que os municípios localizados à Oeste da área de estudo apresentaram mais Ondas de calor, enquanto que à Leste foram mais recorrentes as Ondas de frio. Tal característica 
está relacionada principalmente com a presença do relevo do tipo morros à Leste.

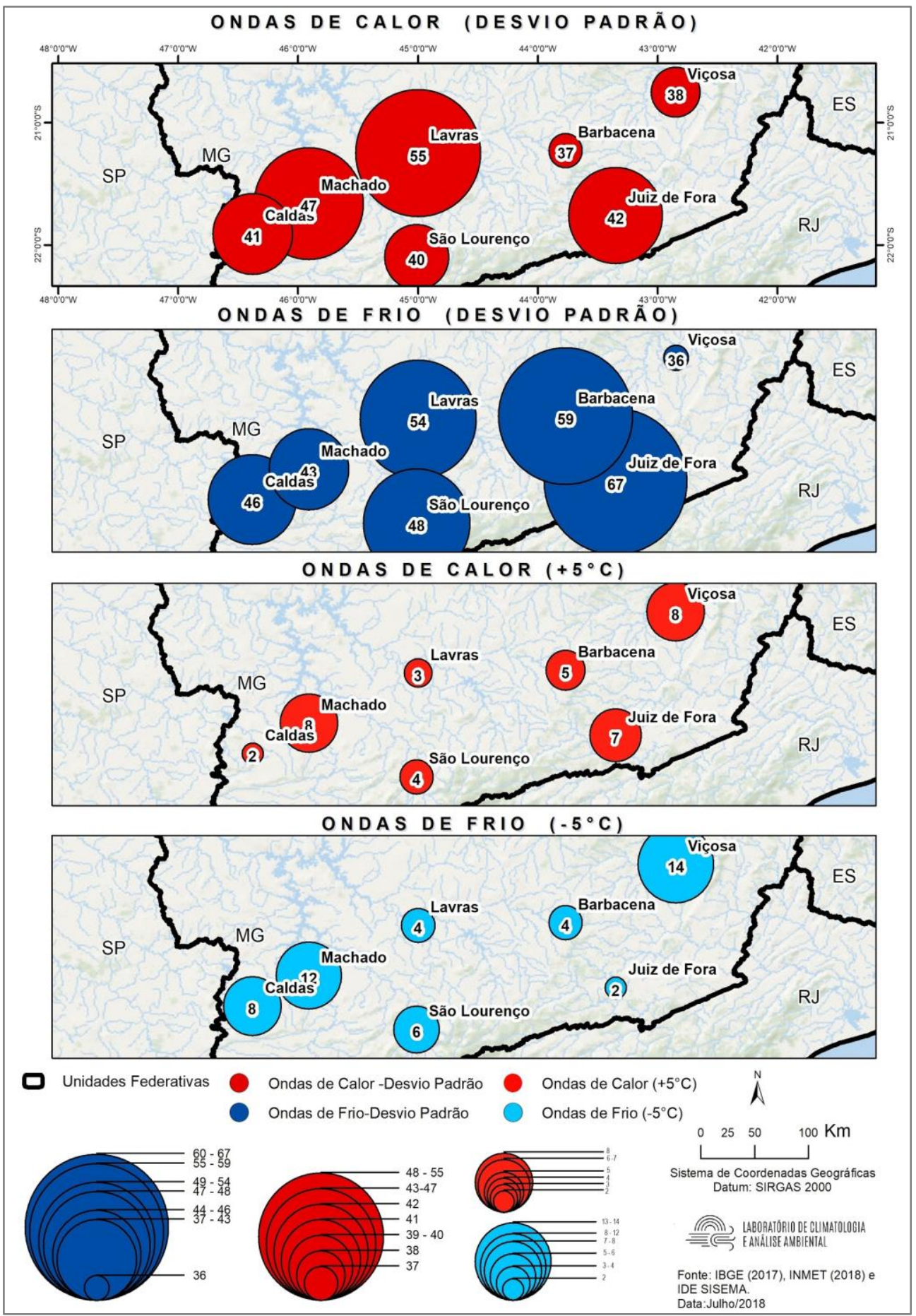

Figura 3 - Quantitativo de Eventos de Ondas por estação meteorológica: Estatísticas de Desvio padrão e $+5^{\circ} \mathrm{C}$ em relação às médias. Fonte: INMET, 2018. Organizado pelos autores. 
Por sua vez, ao considerar o limiar fixo de $5,0^{\circ} \mathrm{C}$ para mais ou para menos de Tmed teve-se uma redução no quantitativo de eventos encontrados. Menos de $15 \%$ dos episódios de Ondas que se enquadraram para os cálculos do desvio padrão não estavam após esse limiar definido, o que implica em dizer que a variação térmica, também, durante os episódios extremos representa a amplitude térmica encontrada na área de estudo.

Os resultados indicaram ainda que o quantitativo de episódios que superaram este limiar é maior para Ondas de frio que para as Ondas de calor, o que significa afirmar que, dada as características de excepcionalidade, as Ondas de frio poderiam exercer maior impacto na região. Como por exemplo, no cultivo do feijão vagem, que diferente dos grãos secos, não tolera longos períodos de baixas temperaturas durante o seu processo de desenvolvimento. Inferior a $10,0^{\circ} \mathrm{C}$, principalmente quando em ocorrência de geadas, pode haver lesões dada a redução das necessidades térmicas da cultura (PRELA, 2002).

Não houve um padrão de distribuição espacial que pudesse ser identificado para esta estatística, mas há locais como Viçosa e Machado que apresentaram quantitativos mais elevados e similares entre episódios de frio e de calor. Se por um lado tais localidades não significaram o maior quantitativo de Ondas pelo desvio padrão, por outro, estão mais propícios à ocorrência de episódios mais intensos (superiores à $5,0^{\circ} \mathrm{C}$ ).

Em relação à intensidade das Ondas (gráfico 1 ), verificou-se que as Ondas climáticas duravam entre 5 e 12 dias e que a maior parte das que foram identificadas teve duração média de 5 dias, representando $36 \%$ das Ondas de calor e $37,6 \%$ das Ondas de frio. Houve diminuição progressiva do quantitativo de Ondas até os 10 dias consecutivos. A partir de 12 dias foram mais escassos os eventos.

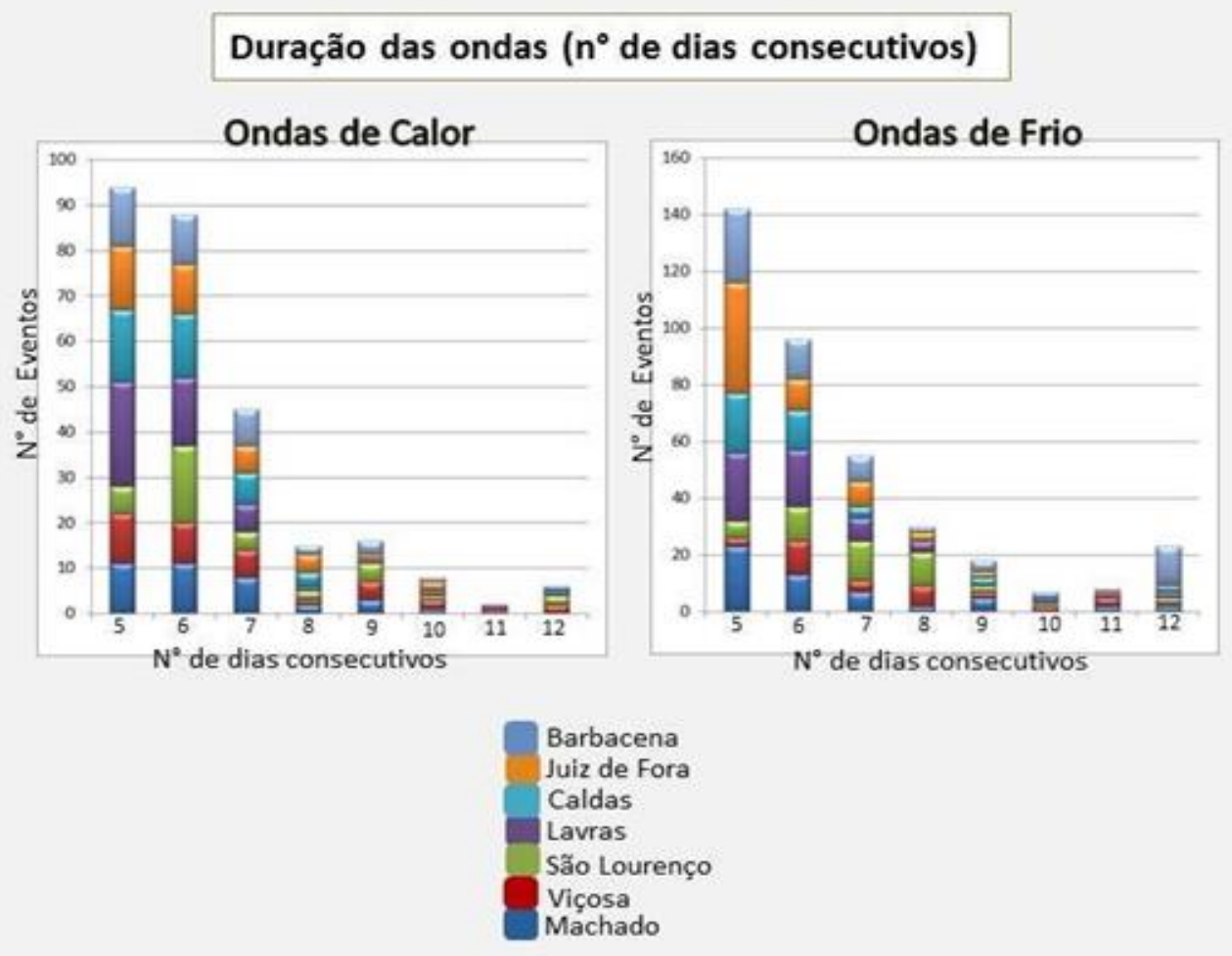


Gráfico 1 - Duração das Ondas de frio e calor em número de dias consecutivos.

No que tange a sazonalidade dos dados (Figura 4) constatou-se que as Ondas de calor ocorrem principalmente nos meses de janeiro e fevereiro, enquanto as Ondas de frio nos meses de abril, julho, agosto e outubro. Tal resultado demonstra correlação entre o regime térmico interanual e a maior ou menor ocorrência de eventos atípicos por período. Em Juiz de Fora, Machado e Caldas a contagem de Ondas de calor demonstrou que não houve sazonalidade nos dados e que foram encontrados valores similares entre as estações do ano. As localidades de Viçosa e Barbacena apresentaram sazonalidade na presença das Ondas, com maior ocorrência no verão e menor no inverno. Em São Lourenço os dados demonstraram maior quantitativo de Ondas na primavera.

Por sua vez, as Ondas de frio apresentaram uma sazonalidade bem marcada para Machado e Viçosa, vindo a apresentar maior ocorrência no inverno. Os municípios de Lavras, Caldas, São Lourenço e Juiz de Fora apresentam na primavera o maior quantitativo de Ondas de frio, enquanto que em Barbacena é no outono. O fato da área de estudo se localizar em uma região considerada fria dentre os climas do Brasil com temperaturas do ar anuais médias variando entre $18,2^{\circ} \mathrm{C}$ em Caldas e $20,3^{\circ} \mathrm{C}$ em Lavras, faz com que os eventos de Ondas de frio se estendam para além do período frio, ocorrendo principalmente durante as estações de transição (primavera e outono). 


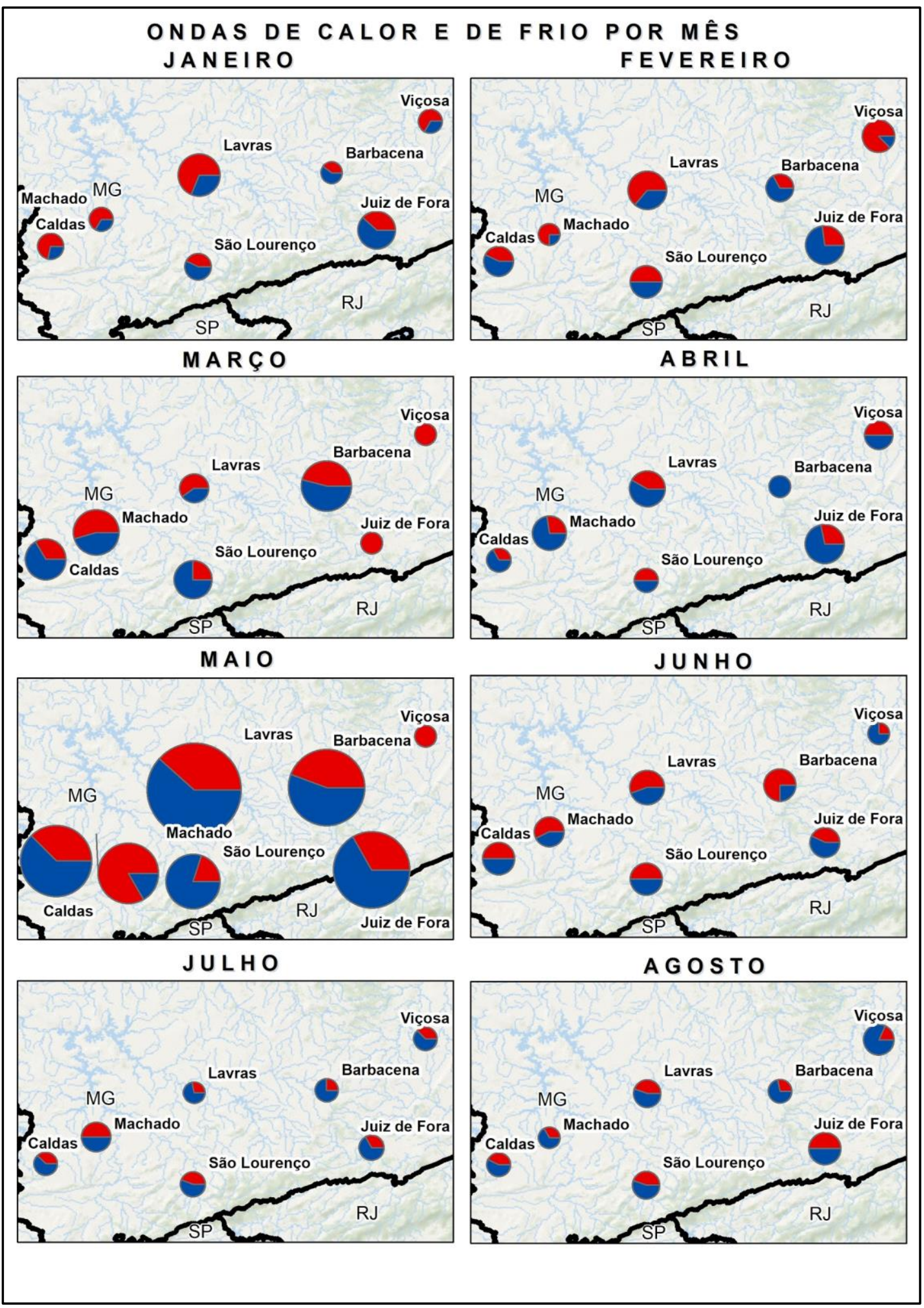




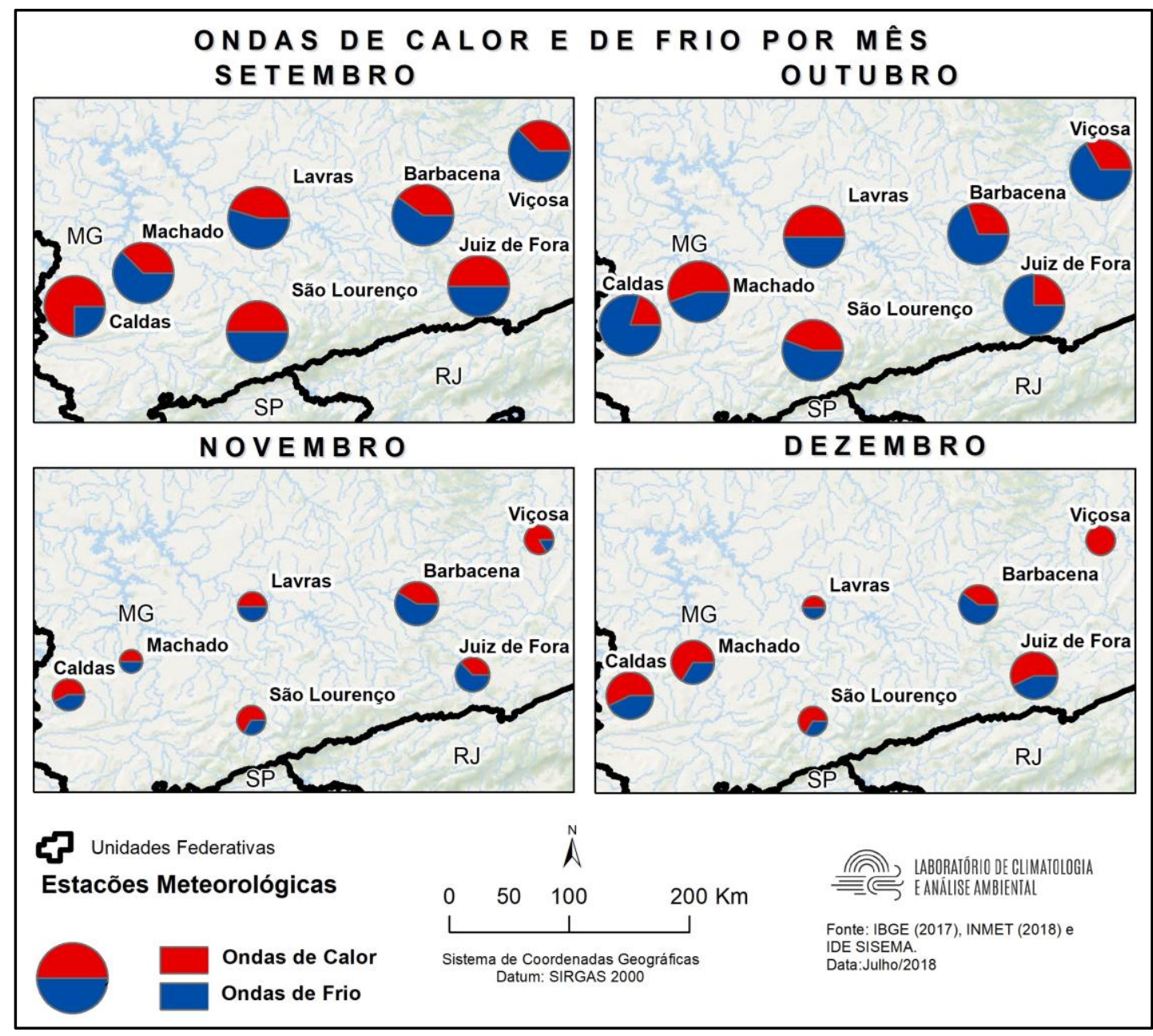

Figura 4 - Quantitativo de ondas por mês, para a série 1993-2011. Distribuição sazonal das Ondas.

\section{CONSIDERAÇÕES FINAIS}

A distribuição espacial dos dados fez constatar que os municípios localizados à Oeste da área de estudo apresentaram maior quantitativo de Ondas de calor, enquanto que os à Leste apresentaram maior quantitativo de Ondas de frio. O emprego das duas metodologias (uma fixa e uma variável) foi satisfatória para a identificação e contagem dos eventos ondulatórios, dado que permitiu observar tanto os Eventos que ocorrem em uma classe de valores próxima à média, como aquela que representa os dados mais extremos já registrados para a área de estudo.

Em termos temporais, constatou-se que os anos de 1994 e 2014 foram aqueles em que foram encontrados os maiores registros de Tmin. e Tmáx., respectivamente, para a área estudada. A sazonalidade marcante, característica da região Sudeste, também se materializou no regime térmico e as estações de transição (Outono e Primavera) foram as que apresentaram o maior quantitativo de Eventos. Nos meses de setembro e outubro foram identificadas mais Ondas de calor, enquanto que em maio um maior quantitativo de Ondas de Frio. 
Os Eventos de Ondas tiveram duração entre 5 e 12 dias mas a permanência média de 5 dias foi a que prevaleceu, o que representou $36 \%$ das Ondas de calor e $37,6 \%$ das Ondas de frio. Houve diminuição progressiva do quantitativo de Ondas até os 10 dias consecutivos.

Espera-se que os resultados obtidos venham a contribuir para a compreensão das tipologias climáticas da região e venha fortalecer os estudos em climatologia.

\section{REFERÊNCIAS BIBLIOGRÁFICAS}

AB'SÁBER, A. N.; Províncias geológicas e domínios morfoclimáticos no Brasil. Geomorfologia. São Paulo. 1970. p.20-26.

ALEIXO, N., SANT'ANNA NETTO, J.L.; CUNHA, L.; Análise comparativa sobre os estudos bioclimáticos no Brasil e em Portugal. Revista Cadernos de Geografia, Coimbra, n.32, 2013. p.57-70.

ALVES, M. P. A.; Ondas de frio invernais em Santa Catarina e suas relações com as variabilidades climáticas de baixa frequência. Dissertação (mestrado em geografia). Florianópolis, 2016.

ALVES, E. J.; Exigências climáticas. A cultura da banana: aspectos técnicos, socioeconômicos e agroindustriais. Brasília: Embrapa-SPI/Embrapa-CNPMF, 1997.

ANDRADE, A. R. et al.; Disponibilidade térmica para diferentes culturas agrícolas em região de clima subtropical úmido obtida através da utilização de índice bioclimático. Geosul, v. 32, n. 64, 2017.

ARMANI, G.; Análise topo e microclimática tridimensional em uma microbacia hidrográfica de clima tropical úmido de altitude. Tese (Doutorado). São Paulo, USP. 2009.

ANDRÉ, R. G. B. et al.; Aspectos energéticos do desenvolvimento da cana-deaçúcar. Parte 1: Balanço de radiação e parâmetros derivados. Revista Brasileira de Meteorologia, v. 25, n. 3,2010

ASSAD, E. D. et al.; Impacto das mudanças climáticas no zoneamento agroclimático do café no Brasil. Pesquisa Agropecuária Brasileira, v. 39, n. 11, 2004.

BARCELLOS, A. MONTEIRO, A.M.V.; CORVALAM, C.; CARVALHO, M.S.; ARTAXO, P.; HACOM, S.; Mudanças climáticas e ambientais e as doenças infecciosas: cenários e incertezas para o Brasil. Epidemiol Serv Saúde. v.18. 2009.

BARRY, R. G.; CHORLEY, R. J.; Atmosfera, tempo e clima. Porto Alegre, RS: Bookmam, 9a edição, 2013.

BERGAMASCHI, H.; MATZENAUER, R.; O milho e o clima. Porto Alegre: Emater/RS-Ascar, 2014.

BITENCOURT, D. P.; FUENTES, M. V.; MAIA, P. A.; AMORIM, F. T.; Frequência, Duração, Abrangência Espacial e Intensidade das Ondas de Calor no Brasil. Revista Brasileira de Meteorologia, vol.31, 2016. 
BOTELHO, F.; GANHO, N.; Episódios de frio extremo em Portugal Continental: análise comparativa de episódios de frio seco e de frio com neve e cotas baixas. Revista Geonorte, ed. especial, Manaus, 2 (4), 2012

BUENO, A. C. R.; A variação da amplitude térmica diária afeta o metabolismo de carbono e o crescimento de mudas de laranjeiras. Dissertação (Mestrado). Campinas, 2011.

CALADO, R.; BOTELHO, J.; CATARINO, J.; CARREIRA, M.; NOGUEIRA, P. J.;, PAIXÃO, E.J.; FALCÃO, J.M.; Onda de calor de Agosto de 2003: os seus efeitos sobre a mortalidade da populacão portuguesa. Revista Nacional de Saúde Pública. 2004.

CARAMORI, P. H. et al. Zoneamento agroclimático para o pessegueiro e a nectarineira no estado do Paraná. Revista Brasileira de Fruticultura, v. 30, n. 4, 2008.

CONTI, J. B.; O meio ambiente Tropical. Geografia, v.14, n.28, 1989.

CRUZ, J.C.; Cultivo do milho. 6.ed. Sete Lagoas: Embrapa Milho e Sorgo, 2010.

CUNHA, L.; Riscos climáticos no Centro de Portugal. Uma leitura geográfica. Revista Geonorte, Edição Especial, v.4, n.4, 2012.

CUNHA, L.; LEAL, C.; Ondas de calor e ondas de frio no município de Torres Novas. Cadernos de Geografia Coimbra, FLUC, n.32, 2013.

ERPEN, L. et al.; Estimativa das temperaturas cardinais e modelagem do desenvolvimento vegetativo em batata-doce. Revista Brasileira de Engenharia Agrícola e Ambiental, v. 17, n. 11, 2013.

ESCOBAR, G.C.J.; Padrões sinóticos associados a ondas de frio na cidade de São Paulo. Revista Brasileira de Meteorologia, v.22, n.2, 2007.

FANTE, K.P.; ARMOND, N.B.; Ondas de frio e enfermidades respiratórias: análise na perspectiva da vulnerabilidade climática. Revista do Departamento de Geografia, Volume Especial, 2016.

FANTE, K.; SANT'ANNA NETO, J. L.; Mudanças nos Padrões da Temperatura do Estado de São Paulo/Brasil nos Últimos 50 Anos. Revista do Departamento de Geografia, v. 33, 2017.

FADEL, R.E.S.; Influência das condições agrometeorológicas na fenologia, qualidade e produtividade de tangerinas na região de Capão Bonito - SP. 2011. Tese (Doutorado).

FERNANDES, A.A.; MARTINEZ, H. E. P.; Produtividade, qualidade dos frutos e estado nutricional do tomateiro tipo longa vida conduzido com um cacho, em cultivo hidropônico, em função das fontes de nutrientes. Horticultura Brasileira, v. 20, n. 4, 2002.

FERNANDES, A.A.; MARTINEZ, H. E. P.; Produtividade, qualidade dos frutos e estado nutricional do tomateiro tipo longa vida conduzido com um cacho, em cultivo hidropônico, em função das fontes de nutrientes. Horticultura Brasileira, v. 20, n. $4,2002$.

FIRPO, M.A.F.; Climatologia das ondas de frio e de calor para o Rio Grande do Sul e sua relação com El Niño e La Niña. Dissertação (Mestrado). Pelotas, 2008. 
FREITAS, F.; Ondas de Calor em Portugal: Impacto Humano e Regimes de Regulação de Risco. Dissertação (Mestrado em Dinâmicas Sociais, Riscos Naturais e Tecnológicos). Coimbra. 2011.

GUERREIRO, V.; Mortalidade e conforto bioclimático em Coimbra estudo da vulnerabilidade das populações ao frio. Tese (mestrado) Coimbra. 2011.

INSTITUTO NACIONAL DE METEOROLOGIA (INMET). Normais Climatológicas do Brasil, 1981- 2010, , Brasília. 2018.

IPCC; Contribution of Working Group II to the Fourth Assessment Report of the Intergovernmental Panel on Climate Change. Organizadores: Parry, M.L., et al. Cambridge University Press, Cambridge, United Kingdom and New York, NY, USA. 2007.

IPMA - Instituto Português do Mar e da Atmosfera: Area Educativa - Onda de Calor. Disponivel em: https://www.ipma.pt/pt/educativa/tempo.clima/index.jsp?page=clima. onda. calo r.xml Acesso em: Setembro de 2018.

KOPPEN, W.; GEIGER, R.; Handbuch der Klimatologie. Borntraeger, Berlin. 5. 1936.

NFELD, J. A.; SILVA, J. B.; ASSIS, F. N.; Temperatura-base e graus-dia durante o vegetativo de três grupos de cultivares de arroz irrigado. Revista Brasileira de Agrometeorologia, v. 6, n. 2, p. 1998.

MARTO, N.; Ondas de calor Imperíodo pacto sobre a saúde. Acta Med Port, v.18, 2005.

MATEUS, K.P.P.; Ondas de Calor e Ondas de Frio em Coimbra, Impactes na Mortabilidade da População. Dissertação (Mestrado em Geografia Física). Coimbra. 2014.

MELLO, R. et al.; ACÚMULO DE GRAUS/DIAS PARA A CULTURA DE CITROS E ANÁLISE DE VENTO NO MUNICÍPIO DE NOVA IGUAÇU DURANTE O ANO DE 2002.

MENDONÇA, M.; ROMERO, H. Ondas de frio, índices de oscilação e impactos socioambientais das variabilidades climáticas de baixa frequência na América do Sul. Edição Especial: "Climatologia Geográfica", Revista Acta Geográfica, v.2. 2012.

MENDONÇA, F.; DANNI-OLIVEIRA, I. M.; Climatologia: noções básicas e climas do Brasil. São Paulo, SP: Oficina de Texto, 2007.

MONTEIRO, C. A. F. Clima e excepcionalismo: conjecturas sobre o desempenho da atmosfera como fenômeno geográfico. Florianópolis: Ed. da UFSC. 1991, $241 p$.

MONTEIRO, A.; ALMEIDA, M., VELHO, S., FONSECA, L.; A (in)eficácia das políticas europeias e nacionais para prevenir os riscos causados pelas manifestações de mudança climática nos espaços urbanos. Revista da Faculdade de Letras - Geografia, Universidade do Porto, III série, v.I, 2012.

MOUCO, M. C. Cultivo da mangueira. Embrapa Semiárido-Sistema de Produção (INFOTECA-E), 2004.

OMM. Reports published through the World Climate Data and Monitoring Programme (WCDMP) series. WCDMP-No.47, WMO-TD No. 1071. 
NASCIMENTO JÚNIOR, L.; As chuvas no Paraná: Variabilidade, teleconexões, e impactos de eventos extremos. Dissertação (mestrado), Presidente Prudente: UNESP. 2013.

NIMER, E.; Climatologia do Brasil. Rio de Janeiro: Instituto Brasileiro de Geografia e Estatística, 1979.

NUNES, L.H. Impacto Pluvial na Serra do Paranapiacaba e Baixada Santista. São Paulo: USP, 1990. Dissertação (Mestrado), Universidade de São Paulo.

NUNES, L.H. Distribuição espaço-temporal da pluviosidade no Estado de São Paulo: tendências, variabilidade, processos intervenientes. São Paulo: USP, 1997. Tese (Doutorado), Universidade de São Paulo.

OLIVEIRA, D.E.; Participação dos sistemas atmosféricos na gênese e ritmo das chuvas na bacia hidrográfica do rio Preto - MG/RJ, anos de 2006, 2007, 2008. Juiz de Fora: UFJF. 2016. Dissertação (Mestrado).

PEZZA, A.B.; Ondas de frio na América do Sul e as trajetórias dos ciclones e anticiclones extratropicais: climatologia sinótica. Tese de Doutorado. Universidade de São Paulo, 2003.

PRELA, A.; RIBEIRO, A. A.; Determinação de graus-dia acumulados e sua aplicação no planejamento do cultivo de feijão-vagem (Phaseolus vulgaris L.) para Londrina-PR. Revista Brasileira de Agrometeorologia, v. 10, n. 1, 2002.

PRELA, A.; RIBEIRO, A. A.; Determinação de graus-dia acumulados e sua aplicação no planejamento do cultivo de feijão-vagem (Phaseolus vulgaris L.) para Londrina-PR. Revista Brasileira de Agrometeorologia, v. 10, n. 1, 2002.

SANT'ANNA NETO, J.L.; Por uma Geografia do Clima, antecedentes históricos, paradigmas contemporâneos e uma nova razão para um novo conhecimento. Revista Terra Livre, $n^{\circ} 17,2001$.

SANTOS, A. O. et al.; Composição da produção e qualidade da uva em videira cultivada sob dupla poda e regime microclimático estacional contrastante. Revista Brasileira de Fruticultura, v. 33, n. 4, 2011.

SILVEIRA, R.B.; ROCHA, G.S.; ALVES, M.P.A.; Contabilização das ondas de frio em Curitiba - Paraná. In: XVII Simpósio Brasileiro de Geografia Física Aplicada, p. 2162-2172, 2017.

SOUZA, A. P. et al.; Temperaturas basais e soma térmica para a figueira podada em diferentes épocas. Revista Brasileira de Fruticultura. Sociedade Brasileira de Fruticultura, v. 31, n. 2, 2009.

STRECKII, L. K. F. N. A.; WALTERIII, H. T. R. L. C.; LOPES, A. J. Z. S.J.; Desenvolvimento, crescimento e produtividade de mandioca em diferentes datas de plantio em região subtropical. Ciência Rural, v. 40, n. 12, 2010.

TAVARES, A.; CUNHA, L.; Riscos naturais e ordenamento do território espaçosrisco e interfaces territoriais na região centro. Actas do VI Congresso da Geografia Portuguesa. Lisboa, 2009.

VALVERDE, O.; Estudo regional da Zona da Mata Mineira. Revista Brasileira de Geografia, Rio de Janeiro, n.1., 1958.

VEYRET, Y.; Os riscos: O homem como agressor e vítima do meio ambiente. Contexto: São Paulo. 2003. Reimpressão 2015 
VERSLYPE, N. I.; CALDAS, R. M. S.; Potencial para o cultivo do caquizeiro na Microrregião do Vale do Ipanema através do modelo digital do terreno. Pitaya/dragon fruit: farming potential in the Sertão of Moxotó through Digital Terrain Model. Revista Geama, v. 2, n. 1, 2016.

VIANELLO, R. L.; ALVES, A. R.. Meteorologia básica e aplicações. Viçosa, MG: UFV, 2012.

WOLLMANN, C.A.; GALVANI, E.; Caracterização climática regional do rio grande do sul: dos estudos estáticos ao entendimento da gênese. Revista Brasileira de Climatologia. Ano.8, v.11. 2012. 